\title{
COMPARISON BETWEEN GREEN TEA EXTRACT AND CASEIN PHOSPHOPEPTIDE AMORPHOUS CALCIUM PHOSPHATE IN TREATMENT OF INCIPIENT CARIES IN PRIMARY TEETH: AN IN VITRO STUDY
}

Mohamed Youssef Ismail *, Nagwa Mohammed Ali Khattab ** and Mona Nagy Mahmoud Hamdi ***

\begin{abstract}
One of the major factors to prevent caries is to retrieve the mineral loss as early as possible through an internal source, which is natural saliva, or an external sources as artificial saliva, available remineralising agents and natural agents. The aim of the present study was to compare the effect of a natural agent called Green Tea Extract (GTE) and a synthetic remineralising agent called Casein Phosphopeptide Amorphous Calcium Phosphate fluoride (CPP-ACPF) in treatment of incipient caries in primary teeth through scanning electron microscope and Energy Dispersive X-Ray Analysis (SEM_EDX).
\end{abstract}

Materials and methods: Fifteen extracted primary teeth were selected and randomly allocated into 2 groups: Group I: CPP-ACPF, Group II: green tea solution of green tea extract. All specimens were scanned with (SEM-EDX), analysis was carried out at baseline, after demineralization and later after remineralisation.

Results: SEM-EDX evaluation showed that the surface minerals content mean value for groups I and II were decreased after demineralization and re-increased after remineralization. SEM also showed improvement in the enamel appearance and the surface became smooth after remineralisation. The surface minerals content mean value in the group treated by CPP-ACPF was higher than the recorded mean value for green tea group.

Conclusions: both CPP-ACPF and green tea extract have comparable remineralisation potential.

KEYWORDS: Casein phosphopeptide-amorphous calcium phosphate fluoride, SEM-EDX, primary teeth, green tea extract, white spot lesions.

* Dentist at Ministry of health, Minia governorate and Graduate Student, Pediatric and Community Dentistry Department Faculty of Dentistry, Minia University Medicine.

** Professor of Pediatric Dentistry and dental public Health, Faculty of Dentistry, Ain Shams University.

*** Lecturer of Pediatric and Community Dentistry, Faculty of Dentistry, Minia University. 


\section{INTRODUCTION}

Dental caries is a contagious biofilm -mediated disease of the tooth described by extended times of $\mathrm{pH}$ under the disintegration $\mathrm{pH}$ of both fluorapatite and hydroxy-apatite, ensuing in total loss of minerals from the tooth ${ }^{(1)}$. In a healthful oral cavity, there could be an ongoing maintained balance occurs through incessant cycles of demineralisation and remineralisation (2). If this balance is ruptured, over a prolonged duration, carious lesion can shape in numerous distinct stages ${ }^{(3)}$.

The earliest stage is the "incipient lesion" characterized by a partial dissolution of tissue and is known as white spot lesion or incipient lesion. The early carious lesion is known to be reversible in nature and can remineralize when treated with proper preventive and remineralisation approach ${ }^{(4)}$.

Recent approaches in treatment of dental caries include lesion management through the control of the lesion rather than on elimination of the tissues that are affected ${ }^{(5)}$. Thus, treatment of cavitated lesions, has been changed into remineralisation which considered a more biological approach and noninvasive strategy ${ }^{(6)}$. Regarding the "early" lesion of caries, there was evidence suggested the use of nonrestorative and noninvasive techniques as remineralisation procedures ${ }^{(7)}$.

Recently, the remineralisation process for the teeth through the using of herbal products instead of chemically based remineralising agents has gained more attention ${ }^{(8)}$. Thus, the current study was conducted to compare the remineralising effect of (GTE) green tea extract to (CPP-ACPF) Casein Phosphopeptide Amorphous Calcium Phosphate fluoride through SEM-EDX.

\section{MATERIALS AND METHOD}

The present study was an in vitro study, with 2 parallel arms. it was approved from research ethic committee, Faculty of Dentistry, Minia University number 235 in 2019.

\section{Test agents used}

- CPP-ACPF “GC Ml paste plus was brought from dental market of Cairo and was made in GC America INC. Alsip, IL60803, U.S. A

- Green tea solution from green tea extract. The green tea leaves were brought from Faculty of Agriculture, Minia University. One hundred grams of dried and grounded green tea leaves were macerated with $500 \mathrm{~mL}$ of ethanol: water (70:30 by volume). The extract was refrigerated for one hour and filtered through a cellulose paper filter. Extraction was repeated twice, each time by $300 \mathrm{~mL}$ of ethanol: water (70: 30 by volume). Then, the filtered extracts were pooled together and dried in water path until evaporation of ethanol, leaving viscous material of green tea extract, which stored in the refrigerator. To prepare the immersion solution, two grams of prepared green tea extract introduced into 180 $\mathrm{mL}$ of boiling water. The sol was cooled off for $5 \mathrm{~min}$. At room temperature ${ }^{(21)}$. The extract was prepared at Nawah Scientific laboratory, Al-mokattam St., Cairo Governorate.

- Solution for demineralization prepared at Faculty of Pharmacy Cairo University. It was prepared through the addition of $2.2 \mathrm{mM} \mathrm{NaH} 2 \mathrm{PO} 4$ and $2.2 \mathrm{mM} \mathrm{CaCl} 2$ to $50 \mathrm{Mm}$ acetic acid which have been adjusted $\mathrm{pH}$ of 4.7 with $1 \mathrm{M} \mathrm{KOH}{ }^{(9)}$.

- Artificial saliva "ARTISIAL" as a remineralising solution was brought from Shop pharmacy, France.

- Thymol solution (0.1\%) was brought from dental market and was made in Foshan Daoqi BioTech Co.,Ltd , China.

\section{Specimens collection}

Sample size of fifteen for each group were estimated using the power calculation $\alpha=0.05$ with $91.7 \%$ being the power of the study. Fifteen deciduous molars indicated for extraction were brought from children have 8-12 years old. Teeth 
were collected from outpatient clinic of Pediatric Dentistry department, Faculty of Dentistry, Minia University. At the outset, an informed consent was signed by the parents for approval to use their children's teeth in research work. Selected teeth were sound free of any signs of caries, structural defects, or cracks. Teeth were cleaned of soft tissue remnants, debris/stains and stored in thymol for maximum 2 months before use ${ }^{(10)}$.

\section{Specimens preparation}

Selected teeth were prepared through two steps, first step was separation of the crown from the root at $2 \mathrm{~mm}$ apical to the cementoenamel junction, second step was sectioning mesiodistally the crown to produce two equal sections, one lingual and the other was buccal using coolant, low speed handpiece and diamond disk to give thirty enamel specimens ${ }^{(11)}$.

\section{Randomization, allocation and grouping the specimens}

After preparation of enamel specimen and Demineralizing regimen, they assigned a numerical denotation (1-30). They were randomly allocated into two groups (15 each) by computer generated block randomization, as following:

Group I:15 enamel specimens treated with CPP$\mathrm{ACPF}$

Group II:15 enamel specimens treated with green tea

\section{Demineralization, caries induction, $\mathrm{pH}$ cycling and application of test agents}

All the specimens were put in $3 \mathrm{ml}$ solution of de-mineralisation at $37^{\circ} \mathrm{C}$ for 96 hours, so an initial carious lesion was produced ${ }^{(12)}$. Each specimen was exhibited to the $\mathrm{pH}$-cycling. Every cycle included two periods of 3-hours of demineralization each, in between the periods; there were 2-hours of remineralisation by artisial. The application of test agents was performed before the $1^{\text {st }}$ and $2^{\text {nd }}$ de-mineralising cycle and after the $2^{\text {nd }}$ de-mineral- ising cycle for one minute; then, all the specimens were put in artisial overnight. Artisial and the pHcycle solutions were refreshed daily.

\section{Specimens evaluation}

All the enamel specimen from all groups were prepared to be examined by SEM-EDX for surface topography and minerals contents ( $\mathrm{Ca}$ and phosphorus $\mathrm{P}$ ), at the baseline, post demineralization and postreminerlaization.

The scanning with SEM-EDX was performed at Central Laboratory for Microanalysis, Minia University.

\section{Statistical analysis}

The data were analyzed by IBM Statistical Package for Social Sciences version 21.0. (IBM corp., Armonk, New York) software using one-way ANOVA, post hoc Tukey's HSD, and paired t-test. $\mathrm{p}<0.05$ was considered statistically significant.

\section{RESULTS}

Energy dispersive X-ray analysis: Calcium and phosphorus levels:

There was statistically significant decrease in mean values of calcium and phosphorus after demineralization process in both groups, with no differences between both groups ( $p>0.05$ )

A statistically significant difference was found in calcium and phosphorus among Post-remineralisation for either in group I (CPP-ACPF) or group II (Green tea). However, group I (CPP-ACPF) had higher mean value in Post-remineralisation than group II (Green tea) for calcium $(\mathrm{p}<0.001)$ and phosphorus, $(\mathrm{p}=0.008)$ Tables $(1 \& 2)$. 
TABLE (1) The mean and standard deviation (SD) values of calcium content in studied groups

\begin{tabular}{|c|c|c|c|c|c|c|}
\hline \multirow{3}{*}{ Variables } & \multicolumn{6}{|c|}{ Calcium } \\
\hline & \multicolumn{2}{|c|}{ Baseline } & \multicolumn{2}{|c|}{ Post demineralization } & \multicolumn{2}{|c|}{ Post remineralisation } \\
\hline & Mean & SD & Mean & SD & Mean & SD \\
\hline Casein amorphous & 51.52 & 3.12 & 29.32 & 1.61 & 43.10 & 2.23 \\
\hline Green tea & 51.73 & 3.30 & 29.02 & 1.53 & 36.11 & 1.88 \\
\hline P-value & \multicolumn{2}{|c|}{$0.860 \mathrm{~ns}$} & \multicolumn{2}{|c|}{$0.601 n s$} & \multicolumn{2}{|c|}{$<0.001 *$} \\
\hline
\end{tabular}

*; significant $(p<0.05)$

TABLE (2) The mean and standard deviation (SD) values of phosphorus content in studied groups

\begin{tabular}{|c|c|c|c|c|c|c|}
\hline \multirow{2}{*}{ Variables } & \multicolumn{4}{|c|}{ Phosphorus } \\
\cline { 2 - 7 } & \multicolumn{2}{|c|}{ Baseline } & \multicolumn{2}{c|}{ Post demineralization } & \multicolumn{2}{c|}{ Post remineralisation } \\
\cline { 2 - 7 } & Mean & SD & Mean & SD & Mean & SD \\
\hline Casein amorphous & 16.75 & 1.53 & 12.41 & 0.85 & 15.69 & 1.71 \\
\hline Green tea & 16.76 & 1.36 & 12.52 & 0.95 & \multicolumn{2}{c|}{$\mathbf{0 . 0 0 8}^{*}$} \\
\hline P-value & \multicolumn{2}{|c|}{$\mathbf{0 . 9 9 1 n s}$} & \multicolumn{2}{|c|}{$\mathbf{0 . 7 2 8 n s}$} & \\
\hline
\end{tabular}

*; significant $(p<0.05)$

\section{Scanning electron microscopy}

Base line: surface topography of sound enamel had smooth and intact surface with honeycomb appearance Figure (1)

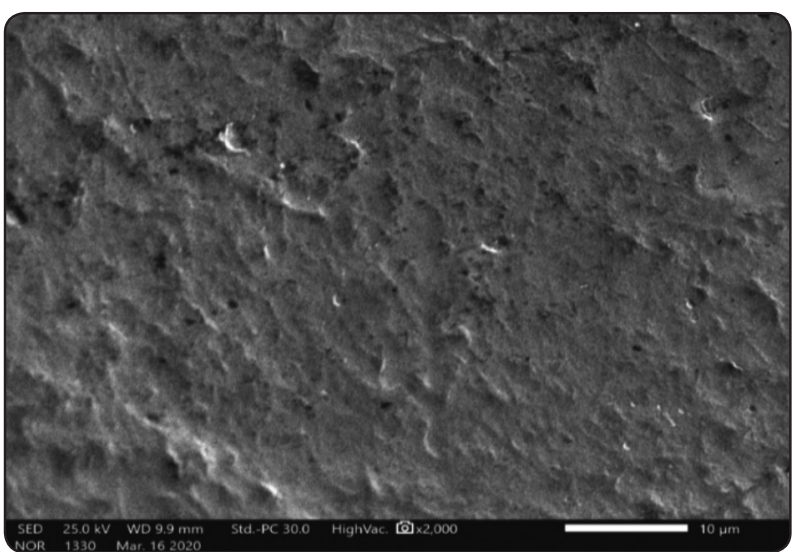

Fig. (1) Photo micrograph of pre-treatment group with magnification $\times 2000$ showing the smooth surface of enamel with little surface deposit.
Postdeminerlaization: a porous appearance and depressions in defined honeycomb pattern were seen and severe surface roughness of the enamel. Figure (2)

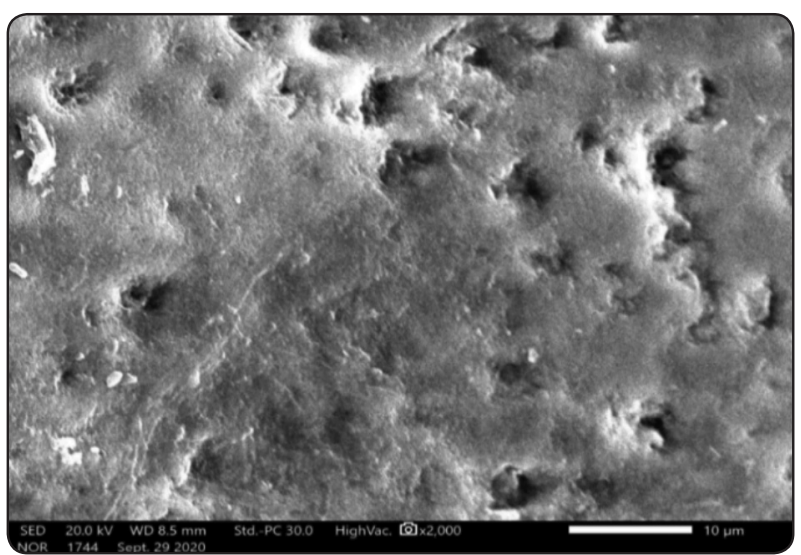

Fig. (2) Photo micrograph of demineralized group with magnification $\times 2000$ showing surface roughness of the enamel 
Postreminerlaization: Deposition of thick homogeneous apatite layer could be observed on enamel surface which did not mimic the natural enamel morphology. Figures (3) and (4).

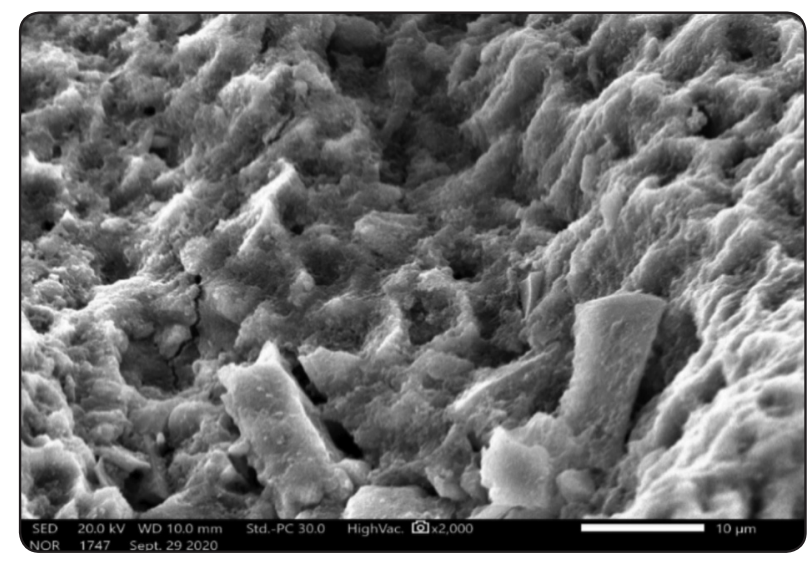

Fig. (3) Photo micrograph of group I treated with CPP-ACPF under magnification $\times 2000$ showing deposition of thick homogeneous apatite layer

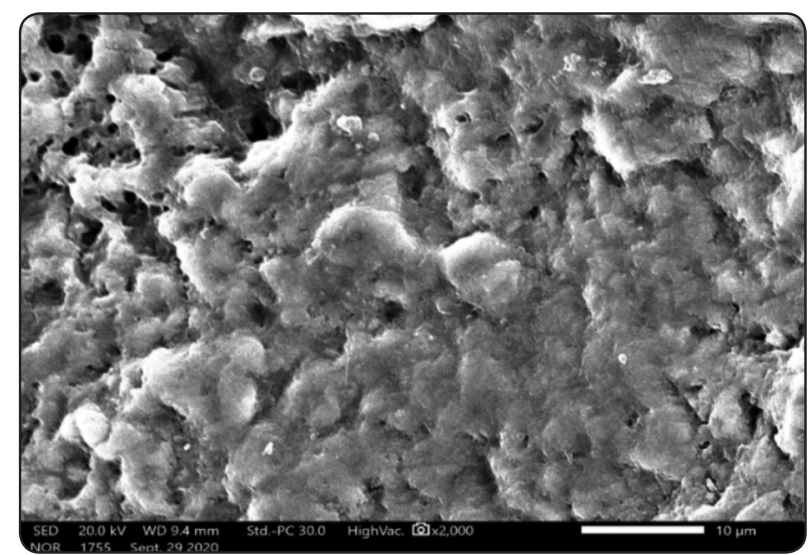

Fig. (4) Photo micrograph of group II treated with green tea under magnification $\times 2000$ showing that surface roughness of enamel is still present

\section{DISCUSSION}

The oral cavity is a battlefield of activities of demineralization and remineralisation, the presence of balance between demineralization and remineralisation is basic to prevent early enamel carious lesions. This balance mediated by the presence of saliva which supply minerals to the tooth $^{(13)}$.
Remineralisation procedures mainly with fluorides or using remineralising agent $\mathrm{CPP}-\mathrm{ACP}$ alone or both of them ${ }^{(14)}$. An interesting addition is plantderived natural products green tea extract which has been found to be effective in inhibiting demineralization, enhancing remineralisation, as well as increasing the efficacy of fluoride ${ }^{(15)}$.

Therefore, the present study was conducted to compare the remineralising effect of (GTE) green tea extract to (CPP-ACPF) Casein Phosphopeptide Amorphous Calcium Phosphate fluoride

GTS was selected because of its antibacterial activity through inhibition of salivary -amylase activities, glucosyltransferase and bacterial growth ${ }^{(16)}$. Also, Green tea is known to contain polyphenols/ catechins like epigallocatechin gallate in large volumes which makes the green tea extract exhibit true functional remineralisation ${ }^{(17)}$.

In the present study green tea was extracted by alcoholic solvent, so the fluoride level not exceeded recommended safe level ${ }^{(18)}$.

In the current study $\operatorname{artisial}^{\mathrm{TM}}$ (artificial saliva for humans) was used as a source for minerals like calcium and phosphate and this was consistent with invitro studies where artificial solutions containing calcium and phosphate can leads to gaining of minerals in incipient lesions formed by the caries either naturally or laboratory-created caries ${ }^{(19)}$.

The preparation of laboratory created early lesions of caries in the present study was in one line with the method performed by Rirattanapong et al. ${ }^{(12)}$, this step resulted in production of a carious lesion with a depth of 60-100 $\mu \mathrm{m}$ and the mineral analysis results at this depth is similar to a naturally created early lesions of caries at the same depth

Also, $\mathrm{pH}$ cycling model used was proposed by Rirattanapong et al. to simulate in vivo conditions occur in humans ${ }^{(12)}$.

SEM-EDX was selected for evaluation for many reasons ; 1) its ability for imaging of the specimen 
surface not its interior, therefore there are no need for the electrons to travel through the specimen, 2) Increasing the field depth so can get a 3 -dimensions images, 3) Increasing the quality and resolution of the images, 4) The ability for serial measurements and 5) It can be used at lower vacuum and allows observation under humid conditions, so, no need for dryness or coating ${ }^{(20)}$.

Treatment of incipient caries in enamel of primary teeth with green tea extract (GTE) and CPPACPF resulted in a significant increase of surface minerals bypassing that of demineralized enamel indicating an effective remineralisation potential of both treatments, table (1) and (2). These results were in agreement with several previous studies ${ }^{(21-}$ 23), who revealed that GTE was able to remineralize enamel surface. High fluoride content of GTE act for converting the tooth surface to be strong resistant to dental caries by formation of fluoridated hydroxyapatite ${ }^{(24)}$.

Also, remineralization potential of green tea extract may be attributed to the active compounds which are divided into two groups: polyphenols or catechins like flavan-3-ols, and minerals and trace elements like fluoride ${ }^{(18)(25)}$.

The remineralising effect of green tea and (CPPACPF) was also confirmed by SEM evaluation where, smooth enamel surface compered to demineralized carious enamel is observed (Figures $(2,3,4))$.

The results of the current study also, revealed that the remineralising ability of (CPP-ACPF) paste is higher than green tea extract (GTE), however the latter is advantageous than (CPP-ACPF) for many reasons; it is natural organic and cheap source for functional foods and its anticariogenic potential. In addition of its antibacterial activity and greater safety ${ }^{(16)(26)(27) . ~}$

\section{The limitations of this in vitro study include:}

1. Simulation of the oral conditions regarding the biological aspects of caries and the multitude of intraoral conditions that contribute to dental caries are very difficult to accurately apply this in the laboratory studies and also the role of enzymes is not accounted for.

2. The current study uses solutions that are composed of inorganic ions only, so the effects of salivary proteins, pellicle and plaque on mineralization inhibition are not taken into consideration.

3. The extraction method, packaging, storage, harvest times and chemotypes are different leads to varying in the chemical composition of the extracts.

4. The presence of experimental faults and various micro-structure of the enamel between specimens.

\section{CONCLOUSIONS}

Based on the findings of the present study, the following conclusions were drawn:

1. Both CPP-ACPF and green tea showed effective remineralisation of incipient enamel caries of primary teeth.

2. CPPACPF showed higher degree of remineralisation than green tea which indicates presence of combined impact between fluoride and CPP

\section{REFERENCES}

1. Kutsch VK, Chaiyabutr Y, Milicich G.: Reconsidering Remineralisation Strategies to Include Nanoparticle Hydroxyapatite. Compend Contin Educ Dent. 2013; 34(3):170-176.

2. Andreadis G and Kalfas S.: Correlation of Dental Plaque Acidogenicity and Acidurance with Caries Activity - Perspectives of the Ecological Plaque Hypothesis. GSTF Journal of Advances in Medical Research (JAMR) 2014;1(1):49-55.

3. Dean J., Jones J., Vinson L., \& McDonald R.: McDonald and Avery's dentistry for the child and adolescent $\left(10^{\text {th }} \mathrm{ed}\right.$., pp. 155-176), 2016. 
4. Roopa KB, Pathak S, Poornima P, Neena IE.: White spot lesions: A literature review. Journal of Pediatric Dentistry 2015; 3(1):1-7.

5. Alkilzy, M., Santamaria, R. M., Schmoeckel, J., \& Splieth, C. H.: Treatment of carious lesions using self-assembling peptides. Advances in dental research 2018; 29(1), 42-47.

6. Schwendicke, F., Frencken, J. E., Bjørndal, L., Maltz, M., Manton, D. J., Ricketts \& Fontana, M.: Managing carious lesions: consensus recommendations on carious tissue removal. Advances in dental research 2016; 28(2), 58-67.

7. Dorri, M., Dunne, S. M., Walsh, T., \& Schwendicke, F.: Micro-invasive interventions for managing proximal dental decay in primary and permanent teeth. Cochrane Database of Systematic Reviews, 2015;(11).

8. Hegde MN, Shetty S and Pardal D.: Remineralisation of enamel sub-surface lesion using Casein Phosphopeptide Amorphus Calcium Phosphate (CPP-ACP) J Conserv Dent 2007;10(1):19-25.

9. Thaveesangpanich P, Itthagarun A, King NM, Wefel JS.: The effects of child formula toothpastes on enamel caries using two in vitro $\mathrm{pH}$-cycling models. International Dental Journal 2005a; 55: 217-23

10. Kamath, P., Nayak, R., Kamath, S. U., \& Pai, Deepika.: A comparative evaluation of the remineralisation potential of three commercially available remineralising agents on white spot lesions in primary teeth: An in vitro study. Journal of Indian Society of Pedodontics and Preventive Dentistry.2017;35(3): 229.

11. VanLoveren $\mathrm{C}$ and Tencate JM.: The effect of triclosen toothpaste on the enamel demineralization in demineralization model of bacteria. journal of antimicrobial chemotherapy.2009;45(2): 153-158.

12. Rirattanapong P, Smutkeeree A, Surarit R, Saendsirinavin C, Kunanantsak V.: Effects of fluoride dentifrice on remineralisation of demineralized primary enamel. Southeast Asian J Trop Med Public Health 2010; 41: 243-9.

13. Soares R, De Ataide IN, Fernandes M, Lambor R.: Assessment of Enamel Remineralisation After Treatment with Four Different Remineralising Agents .J clinc Diag Res 2017 ; Apr 11(4): 136-41.

14. Gupta N, Mohan Marya C, Nagpal R, Singh Oberoi S, Dhingra $\mathrm{C}$.: A review of casein phosphopeptide-amorphous calcium phosphate (CPP-ACP) and enamel remineralisation. Compend Contin Educ Dent. 2016; 37(1):36-39

15. Singh BN, Shankar S and Srivastava RK.: Green tea catechin, epigallocatechin-3-gallate (EGCG): Mechanisms, perspectives and clinical applications. Biochem Pharmacol. 2011; 82:1807-21; 2011.
16. Chow HH, Hakim IA, Vining DR, Crowell JA, RangerMoore J, Chew WM, et al.: Effects of dosing condition on the oral bioavailability of green tea catechins after singledose administration of Polyphenon E in healthy individuals. Clin Cancer Res. 2005; 11:4627-33.

17. Jose, Poornima, Kavitha Sanjeev, and Mahalaxmi Sekar.: "Effect of green and white tea pretreatment on remineralisation of demineralized dentin by CPP-ACFP-an invitro microhardness analysis." Journal of clinical and diagnostic research: JCDR 2016, 10.4: ZC85.

18. Karak T, Bhagat RM.: Trace elements in tea leaves, made tea and tea infusion: A review. Food Res Int. 2010; 43:2234-52.

19. Narmarata patil, shantanu chaydani.: Comparative evaluation of remineralising potential of three agents on artificially demineralized human enamel: An In Vitro study. Jour of conserv. Dent. 2013;16-116:20.

20. Buzalaf MA, Hannas AR, Magalhaes AC, Rios D, Honorio HM, Delbem AC.: $\mathrm{pH}$-cycling models for in vitro evaluation of the efficacy of fluoridated dentifrices for caries control: strengths and limitations. J Appl Oral Sci. 2010; 18:316-34.

21. Mirkarimi M and Toomarian L.: Effect of green tea extract on the treatment of dentin erosion: an in vitro study. Journal of dentistry (Tehran, Iran), 2012; 9(4): 224-228

22. Jaâfoura S, Khemiss F, Kammoun D, Chebbi R, accouche $\mathrm{C}$ and Ghoul-Mazgar S.: Dental erosion and tea: A systematic review. Tnt J Sci Res, Nov 2014; 3 (11):300-358.

23. De Moraes MD, Carneiro JR, Passos VF and/Santiago SL.: Effect of green tea as a protective measure against dental erosion in coronary dentine. Braz Oral Res, 2016; 30(1): e13

24. Ganss C, Lussi A, Grunau O, Klimek J and Schlueter N.: Conventional and anti-erosion fluoride toothpastes: effect on enamel erosion and erosion-abrasion. Caries Res, 2011; 45: 581-589.

25. Chaturvedula, V. S. P. \& Prakash, I.: The aroma, taste, color and bioactive constituents of tea. J. Med. Plants Res. 2011; 5, 2110-2124.

26. Zhang X, Li Y, Sun X, Kishen A, Deng X, Yang X, Wang $\mathrm{H}$, Cong C, Wang Y, Wu M.: Biomimetic remineralisation of demineralized enamel with nano-complexes of phosphorylated chitosan and amorphous calcium phosphate. J Mater Sci Mater Med. 2014;25(12):2619-2628.

27. Wu, Christine D., and G. Wei.: "Tea as a functional food for oral health." Food constituents and oral health. Woodhead Publishing, 2009. 396- 